\title{
The effects of Spirulina Platensis on
} anthropometric indices, appetite, lipid profile and serum vascular endothelial growth factor (VEGF) in obese individuals: a randomized double blinded placebo controlled trial

\author{
Reihaneh Zeinalian ${ }^{1}$, Mahdieh Abbasalizad Farhangi ${ }^{2^{*}}$, Atefeh Shariat ${ }^{3}$ and Maryam Saghafi-Asl ${ }^{1}$
}

\begin{abstract}
Background: In recent years, a great attention has been focused on Spirulina platensis as a source of potential valuable nutrients for prevention and treatment of chronic diseases. The objectives of the current study were to determine the effects of Spirulina platensis on anthropometric parameters, serum lipids, appetite and serum Vascular Endothelial Growth Factor (VEGF) in obese individuals.
\end{abstract}

Methods: In the current study sixty four obese individuals aged 20-50 years were enrolled and randomly allocated into two groups of intervention and placebo. Intervention group $(n=29)$ received each 500 mg of the Spirulina platensis a twice-daily dosage while the control group $(n=27)$ received two pills daily starch for 12 weeks. Anthropometric parameters and serum VEGF and lipid profile were measured in fasting blood samples at the beginning and end of the study period. Dietary intakes were assessed by a 24-h recall method and appetite was measured using standard visual analogue scale (VAS).

Results: Body weight and body mass index (BMI) were decreased in intervention and placebo treated groups although the mean reduction in Spirulina platensis-treated group was significantly higher $(P<0.05)$. Serum total cholesterol (TC) significantly reduced in intervention group $(P<0.05)$. Also, treatment with Spirulina platensis significantly reduced appetite $(P=0.008)$. Mean serum VEGF, low density lipoprotein-cholesterol, and triglycerides did not change significantly after intervention. Serum high density lipoprotein-cholesterol concentrations (HDL-c) significantly increased in both groups while no difference in mean difference of this change has been observed.

Conclusion: Spirulina supplementation at a dose of $1 \mathrm{~g} / \mathrm{d}$ for 12 weeks is effective in modulating body weight and appetite and partly modifies serum lipids. This can further confirm the efficacy of this herbal supplement in control and prevention of obesity and obesity- related disorders.

Trial registration: Iranian registry of clinical trials (IRCT registration number: IRCT2015071219082N7; Date registered: September 12, 2015).

Keywords: Spirulina Platensis, Vascular endothelial growth factor (VEGF), Lipid profile, Appetite

\footnotetext{
* Correspondence: Abbasalizad_m@yahoo.com

${ }^{2}$ Drug Applied Research Center, Nutrition Research Center, Department of

Nutrition in Community, Faculty of Nutrition, Tabriz University of Medical

Sciences, Tabriz, Iran

Full list of author information is available at the end of the article
} 


\section{Background}

Obesity is one of the main health problems throughout the world and its prevalence is increasing rapidly [1]. Obesity is associated with numerous health related comorbidities like cardiovascular events, diabetes, metabolic syndrome, hypertension and even some types of cancers [2]. According to the recent report by the World Health Organization (WHO), in 2014 more than 600 million adults were obese. Overweight and obesity are the fifth leading risk for global deaths [3]. At least 2.8 million adults die each year as a result of obesity [2, 4].

Diet and physical activity play an important role in regulating weight. In recent years use of herbs for weight loss has been dramatically increased, because of fewer side effects of herbal remedies [1, 5]. Recent studies reported that long-term obesity causes the release of some factors that can promote proliferative disorders in the gland, culminating in diffuse hyperplasia [6]. As observed in human adipose tissue, one mechanism for an increased inflammatory response may arise through activation of the innate immune system [7]. Adipose tissue contains abundant endothelial cells that could secrete angiogenic factors, such as vascular endothelial growth factor (VEGF) [8]. VEGF is an important angiogenic factor implicated in normal and pathological vessel formation [9], which is an important biomarker in obesity and obesity-related cancer progression [10]. Increased serum VEGF concentrations due to visceral fat accumulation could also influence vascular endothelial function [9].

On the other hand, many supplements have been manufactured in order to decrease obesity and its negative consequences on health. Spirulina (Arthrospira platensis) is a filamentous cyanobacterium used as a food supplement [11]. WHO projects that Spirulina will become one of the most curative and prophylactic components of nutrition in the twenty-first century [12]. It is not expensive and some researchers have even named it a "super-food" [13]. In recent years, great attention has been paid to Spirulina platensis as a source of a potential treatment for many diseases [14-17]. Very limited studies evaluated the anti-obesity effects of Spirulina platensis. In one animal model by Balasubramanian et al. [18], treatment with Spirulina platensis significantly reduced weight in high fat diet induced obese rats. To our review of literature, no human study was available examining the effects of Spirulina platensis on obesity and its metabolic consequences. We hypothesized that Spirulina platensis treatment is capable of modulating serum lipids, body weight, appetite control and reducing serum VEGF concentrations. Therefore, the objectives of the current study was to determine the effects of a twice-daily dosage (each $500 \mathrm{mg}$ ) of the Spirulina platensis supplement for 12 weeks on anthropometric features, lipid profile, appetite and serum VEGF concentrations in obese individuals.

\section{Methods}

\section{Study design}

In the current randomized double blind placebo-controlled trial sixty four obese individuals aged $20-50$ years were enrolled (Fig. 1). Inclusion criteria included: BMI $\geq 30 \mathrm{~kg} / \mathrm{m}^{2}$ and age of 20-50 years. Exclusion criteria included: any history of kidney diseases, atherosclerosis, cancer, acute

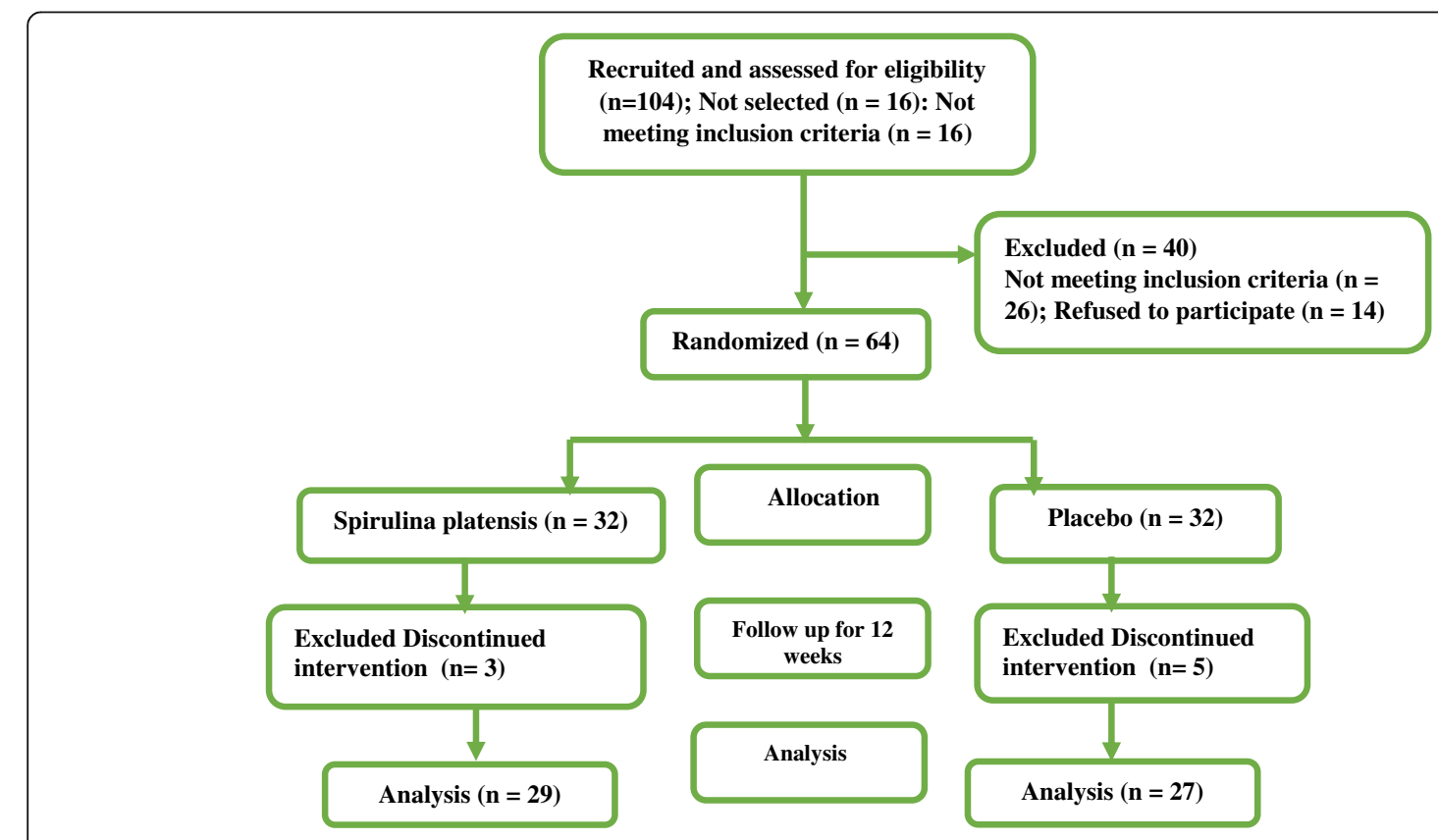

Fig. 1 Study flowchart 
infections, recent surgery, use of hormonal medications, anti-depressive medications, antibiotics, anti-diuretics, glucocorticoids and using vitamin or mineral supplements in the past three months, pregnancy, lactation, menopause and being on weight losing diets in the past three months. The protocol the current study was approved by the ethics committee of Tabriz University of Medical Sciences (Registration number: 1394.461). Individuals were informed about the study aims and a time of 10 days prior participation in the trial was given to them to announce their participation in the study. Written informed consent was obtained from all participants.

\section{Intervention}

Participants were allocated to treatment groups by simple randomization. They were divided into two groups, matched by age and gender. In the intervention group $(n=29)$, a twice-daily dosage (each $500 \mathrm{mg}$ ) of the Spirulina platensis supplement (Far East Microalgae Ind. Co., LTD, Femico, Taiwan) was administered. The contents of Spirulina platensis supplement are presented in Table 1. The control group $(n=27)$ received two pills daily, which contained one gram starch without chlorophyll as a placebo

Table 1 Contents of the Spirulina platensis supplement ${ }^{\mathrm{a}}$

\begin{tabular}{ll}
\hline Spirulina platensis ingredients & Content (per gram) \\
\hline Total protein & $550-670 \mathrm{mg}$ \\
Total fat & $60-80 \mathrm{mg}$ \\
Total fiber & $20-60 \mathrm{mg}$ \\
chlorophyll & $15 \mathrm{mg}$ \\
Total ash & $60-80 \mathrm{mg}$ \\
carbohydrate & $120-200 \mathrm{mg}$ \\
Moisture & $40-60 \mathrm{mg}$ \\
Beta Carotene & $2.58 \mathrm{mg}$ \\
Vitamin E & $0.066 \mathrm{mg}$ \\
Niacin & $0,16 \mathrm{mg}$ \\
Phosphorus & $9.14 \mathrm{mg}$ \\
Sodium & $1.86 \mathrm{mg}$ \\
Calcium & $1.71 \mathrm{mg}$ \\
Magnesium & $2.6 \mathrm{mg}$ \\
Potassium & $17.7 \mathrm{mg}$ \\
Iron & $0.75 \mathrm{mg}$ \\
Zinc & $0.05 \mathrm{mg}$ \\
Vitamin B1 & $48 \mathrm{mg}$ \\
Vitamin B2 & $42 \mathrm{mg}$ \\
Vitamin B6 & $7 \mathrm{mg}$ \\
Vitamin B12 & $2.3 \mathrm{mg}$ \\
Biotin & $0.25 \mathrm{mg}$ \\
Folic Acid & $0.61 \mathrm{mg}$ \\
\hline &
\end{tabular}

Provided by Far East Microalgae Ind. Co., LTD, Femico, Taiwan in similar-looking and shape with spirulina platensis pills. The duration of study was 12 weeks. Participants were followed by phone contacts every 7 days, in order to verify that they had taken the pills. Participants were also asked some questions in order to ascertain whether or not they kept to their usual diet. They were requested not to take any mineral or vitamin supplements and also not to change their normal diet or their usual physical activity.

\section{Anthropometric and dietary assessments}

Body weight was measured with a calibrated digital scale and height was measured with a stadiometer. BMI was calculated as weight $(\mathrm{kg})$ divided by height $(\mathrm{cm})$ squared. During the anthropometric measurements, subjects wore lightweight clothing and no shoes. Weight was measured to the nearest $0.1 \mathrm{~kg}$ and height was measured to the nearest $0.1 \mathrm{~cm}$. Dietary intakes were assessed by a 24-h food-recall for three days (two on working days and one on a weekend) at the beginning and at end of the study, in order to determine if there was a major modification in the individuals' usual dietary intake that would exclude them from analysis. Dietary intakes were analyzed by Nutritionist IV software.

\section{Measurements of appetite}

Appetite was measured with visual analogue scale (VAS). VAS is a standard tool used to measure subjective appetite completed before and after every meal. VAS includes 10 items about feeling of hunger, fullness, appetite, satiety, thirst, prospective food consumption and desire to eat. Moreover, VAS is most often composed of lines (of varying length) with words anchored at each end, describing the extremes (that is, "I have never been more hungry"/ "I am not hungry at all"). Subjects were asked to make a mark across the line corresponding to their feelings. Quantification of the measurement was done by measuring the distance from the left end of the line to the mark [19]. These scales were administered at intervals of 10-30 min during studies. Subjects were familiarized with these scales prior to the commencement of the study.

\section{Physical activity level}

The questionnaire with nine different metabolic equivalent (MET) scales ranging from sleep/rest (0.9 METs) to high-intensity physical activates ( $>6$ METs) was used to determine physical activity levels. The MET values were multiplied by the time spent at that particular level for each activity level. At each level, the MET-time was added to obtain a total over $24 \mathrm{~h}$ MET-time, demonstrating the physical activity level on an average day. Physical activities of different intensities were rated to three categories, termed as sedentary ( $<3 \mathrm{METs})$, moderate (3-6 METs) and vigorous ( $>6$ METs) [20]. 


\section{Biochemical assays}

Fasting blood samples were taken at the beginning and end of the twelve weeks of intervention. The serum and plasma samples were separated by centrifugation at $2500 \mathrm{rpm}$ for 10 min (Beckman Avanti J-25; Beckman Coulter, Brea, CA, USA) at room temperature. The serum samples were stored at $-70{ }^{\circ} \mathrm{C}$ immediately after centrifugation. Serum VEGF was measured with the Human VEGF ELISA Kit (Hangzhou East biopharm Co., LTD, USA). The intra-assay and inter-assay coefficient of variation $(\mathrm{CV})$ for VEGF assessment were $<15 \%$. Serum lipids were assessed by Abbott ALCYON ${ }^{\mathrm{Ts}} 300$ auto analyzer using commercial ELISA kits (Pars-Azmoon, Tehran, Iran). All of the biochemical assays were performed by a trained lab assistant who was blinded to group assignments. Serum low density lipoprotein cholesterol- concentrations (LDL-c) was calculated by Friedewald formula [21].

\section{Statistics}

Statistical analysis was performed with the Statistical Package for Social Sciences (SPSS) version 21of software package (SPSS Inc., Chicago, IL, USA). The KolmogorovSmirnov test was used to assess the normality of the data. Quantitative data were presented as mean \pm standard deviation (SD), and qualitative data were demonstrated as frequency and percent. A Chi-square test was performed to determine differences at the baseline in frequencies of categorized variables between the groups. Between the groups, comparisons of continuous variables were performed by independent sample $\mathrm{t}$-tests. The paired $t$-test was used to analyze intra-group change of all measured parameters between the baseline and end of the intervention period. Analysis of covariance (ANCOVA) was used to identify any differences between the two treatment groups after intervention, adjusting for the confounding effects of baseline concentrations of parameter, age, gender and physical activity level in three models. $P$ value of less than 0.05 was considered statistically significant. Sample size calculation was performed based on $80 \%$ power and an a-error of 5\% to detect treatment effect of Spirulina platensis on serum LDL-c [22]; a total of 28 individuals were calculated in each group. Allowing for $15 \%$ drop-out over 12 weeks of intervention, the total sample size required for the study is 64 individuals with 32 individuals in each group.

\section{Results}

\section{General characteristics of trial and drop-outs}

The flowchart of the study has been shown in Fig. 1. In Spirulina platensis group three participants and in control group five participants declined to continue the trial. Finally 56 individuals completed the study. In the current study no side effects of treatment were observed.
Table 2 General characteristics of study participants

\begin{tabular}{lllll}
\hline Variable & & Spirulina platensis & Placebo & $P \dagger$ \\
\hline Gender $[n(\%)]$ & Male & $5(17.2)$ & $4(14.8)$ & 0.81 \\
& female & $24(82.8)$ & $23(85.2)$ & \\
Age (y) & & $34.75 \pm 8.04$ & $33.92 \pm 8.57$ & 0.71 \\
Physical activity & & & & \\
Before & Low & $16(55.2)$ & $12(44.4)$ & 0.80 \\
& Moderate & $12(41.4)$ & $14(51.9)$ & \\
& High & $1(3.4)$ & $1(3.7)$ & \\
After & Low & $11(37.9)$ & $6(22.2)$ & 0.91 \\
& Moderate & $17(58.6)$ & $20(74.1)$ & \\
& High & $1(3.4)$ & $1(3.7)$ & \\
Pł & & 0.03 & 0.12 & \\
\hline
\end{tabular}

t $P$ values for independent $t$-test, $\neq P$ values for paired $t$-test. The statistically significant values are presented as italic digits

Table 3 Dietary intake of energy, macro and micronutrients in study groups before and after treatment

\begin{tabular}{|c|c|c|c|c|}
\hline Variable & & $\begin{array}{l}\text { Spirulina platensis } \\
\text { (Mean } \pm \text { SD) }\end{array}$ & $\begin{array}{l}\text { Placebo } \\
\text { (Mean } \pm \text { SD) }\end{array}$ & P† \\
\hline Energy (kcal) & $\begin{array}{l}\text { Before } \\
\text { After } \\
p^{\ddagger}\end{array}$ & $\begin{array}{l}2289.51 \pm 436.48 \\
2289.96 \pm 361.78 \\
0.99\end{array}$ & $\begin{array}{l}2305.71 \pm 298.84 \\
2266.47 \pm 347.24 \\
0.40\end{array}$ & 0.418 \\
\hline Protein (gr) & $\begin{array}{l}\text { Before } \\
\text { After } \\
p^{\neq}\end{array}$ & $\begin{array}{l}103.8 \pm 25.58 \\
110.5 \pm 26.19 \\
0.06\end{array}$ & $\begin{array}{l}110.24 \pm 31.9 \\
113.14 \pm 24.8 \\
0.62\end{array}$ & 0.70 \\
\hline Carbohydrate (gr) & $\begin{array}{l}\text { Before } \\
\text { After } \\
p^{\ddagger}\end{array}$ & $\begin{array}{l}303.67 \pm 105.27 \\
299.34 \pm 81.63 \\
0.73\end{array}$ & $\begin{array}{l}302.3 \pm 79.58 \\
304.13 \pm 61.48 \\
0.9\end{array}$ & 0.80 \\
\hline Fat (gr) & $\begin{array}{l}\text { Before } \\
\text { After } \\
p^{\ddagger}\end{array}$ & $\begin{array}{l}73.67 \pm 28.54 \\
70.54 \pm 20.03 \\
0.4\end{array}$ & $\begin{array}{l}67.49 \pm 24.61 \\
68.77 \pm 21.48 \\
0.79\end{array}$ & 0.75 \\
\hline Protein (\%) & $\begin{array}{l}\text { Before } \\
\text { After } \\
P^{\neq}\end{array}$ & $\begin{array}{l}18.20 \pm 4.10 \\
18.72 \pm 5.58 \\
0.5\end{array}$ & $\begin{array}{l}19.59 \pm 5.92 \\
19.25 \pm 3.85 \\
0.79\end{array}$ & 0.68 \\
\hline Carbohydrate (\%) & $\begin{array}{l}\text { Before } \\
\text { After } \\
P^{\neq}\end{array}$ & $\begin{array}{l}50.37 \pm 12.37 \\
51.96 \pm 8.55 \\
0.54\end{array}$ & $\begin{array}{l}54.48 \pm 9.54 \\
53.07 \pm 6.75 \\
0.54\end{array}$ & 0.59 \\
\hline Fat (\%) & $\begin{array}{l}\text { Before } \\
\text { After } \\
P^{\ddagger}\end{array}$ & $\begin{array}{l}27.95 \pm 8.57 \\
29.1 \pm 6.78 \\
0.36\end{array}$ & $\begin{array}{l}25.92 \pm 7.42 \\
28.92 \pm 10.66 \\
0.18\end{array}$ & 0.94 \\
\hline Vitamin E(mg) & $\begin{array}{l}\text { Before } \\
\text { After } \\
p^{\neq}\end{array}$ & $\begin{array}{l}9.75 \pm 8.34 \\
11.02 \pm 11.58 \\
0.316\end{array}$ & $\begin{array}{l}8.00 \pm 9.2 \\
10.23 \pm 10.27 \\
0.21\end{array}$ & 0.14 \\
\hline Vitamin C(mg) & $\begin{array}{l}\text { Before } \\
\text { After } \\
p^{\neq}\end{array}$ & $\begin{array}{l}81.23 \pm 39.94 \\
93.05 \pm 33.43 \\
0.12\end{array}$ & $\begin{array}{l}74.36 \pm 43.35 \\
67.92 \pm 33.31 \\
0.41\end{array}$ & 0.007 \\
\hline Selenium(mg) & $\begin{array}{l}\text { Before } \\
\text { After } \\
p^{\ddagger}\end{array}$ & $\begin{array}{l}0.1 \pm 0.05 \\
0.14 \pm 0.18 \\
0.25\end{array}$ & $\begin{array}{l}0.12 \pm 0.17 \\
0.08 \pm 0.04 \\
0.33\end{array}$ & 0.1 \\
\hline
\end{tabular}

$\neq P$ values for paired $t$-test; $+P$ values based on ANCOVA after adjustment for age, gender, physical activity, and variable's baseline value. The statistically significant values are presented as italic digits 


\section{Demographic parameters, physical activity level and nutrients intake}

Demographic parameters and physical activity levels of the subjects are reported in Table 2. No significant difference in gender distribution and physical activity level was observed at the beginning and end of treatment. The intake of nutrients during the study was constant and was comparable between the groups (Table 3).

\section{Change in anthropometric and biochemical parameters}

BMI had significantly decreased in both groups and its mean reduction in Spirulina platensis-treated group was significantly higher compared with placebo-treated group. Serum VEGF had not statistically changed
(Table 4).There were no significant differences on TG and LDL in the intervention or control group. HDL significantly increased in both intervention and control group $(P<0.05)$, although mean differences of change in serum HDL-c between groups were not significant $(P=0.514)$. Total cholesterol had significantly decreased in subjects who received Spirulina $(P=0.002)$, whereas there was no significant difference in the control group $(P=0.086)$. Treatment with Spirulina platensis also significantly reduced appetite $(P=0.008)$. No change in serum VEGF and other serum lipids were observed. Adjustment for the confounding effects of variables baseline concentrations, age, gender and physical activity was performed by ANCOVA test in three models

Table 4 Anthropometric and metabolic parameters in study groups before and after treatment

\begin{tabular}{|c|c|c|c|c|c|c|}
\hline \multirow[t]{2}{*}{ Variable } & & \multicolumn{4}{|l|}{ Treatment Groups } & \multirow[t]{2}{*}{$p^{\neq}$} \\
\hline & & Spirulina platensis & Percent change & Placebo & Percent change & \\
\hline \multirow[t]{3}{*}{ Weight(kg) } & Before & $89.62 \pm 11.54$ & 1.79 & $87.66 \pm 13.64$ & 0.71 & 0.007 \\
\hline & After & $88.01 \pm 11.42$ & & $87.03 \pm 13.70$ & & \\
\hline & $P+$ & $<0.001$ & & 0.09 & & \\
\hline \multirow[t]{3}{*}{$\mathrm{WC}(\mathrm{cm})$} & Before & $98.89 \pm 8.48$ & 1.40 & $101.07 \pm 9.56$ & 0.66 & 0.059 \\
\hline & After & $97.50 \pm 8.39$ & $100.40 \pm 9.77$ & & & \\
\hline & Pt & 0.00 & 0.003 & & & \\
\hline \multirow[t]{3}{*}{ BMI $(\mathrm{kg} / \mathrm{m} 2)$} & Before & $33.35 \pm 2.81$ & -1.90 & $32.71 \pm 3.18$ & -0.73 & 0.005 \\
\hline & After & $32.71 \pm 2.80$ & & $32.47 \pm 3.24$ & & \\
\hline & $P+$ & $<0.001$ & & 0.01 & & \\
\hline \multirow[t]{3}{*}{ VEGF(ng/l) } & Before & $3.22 \pm 0.37$ & 0.14 & $3.20 \pm 0.28$ & 0.25 & 0.580 \\
\hline & after & $3.22 \pm 0.37$ & & $3.21 \pm 0.29$ & & \\
\hline & $P+$ & 0.775 & & 0.735 & & \\
\hline \multirow[t]{3}{*}{$\mathrm{TG}(\mathrm{mg} / \mathrm{dl})$} & Before & $144.13 \pm 57.57$ & -3.84 & $156.14 \pm 79.01$ & -7.31 & 0.486 \\
\hline & after & $136.65 \pm 60.80$ & & $140.88 \pm 72.73$ & & \\
\hline & $P+$ & 0.365 & & 0.052 & & \\
\hline \multirow[t]{3}{*}{ LDL(mg/dl) } & Before & $116.27 \pm 34.79$ & -2.06 & $119.90 \pm 21.69$ & -2.05 & 0.725 \\
\hline & after & $115.42 \pm 28.61$ & & $116.68 \pm 21.31$ & & \\
\hline & $P+$ & 0.886 & & 0.196 & & \\
\hline \multirow[t]{3}{*}{$\mathrm{HDL}(\mathrm{mg} / \mathrm{dl})$} & Before & $36.55 \pm 10.21$ & 1.73 & $34.88 \pm 11.56$ & 4.36 & 0.385 \\
\hline & after & $38.75 \pm 8.84$ & & $38.37 \pm 9.44$ & & \\
\hline & $P+$ & 0.05 & & 0.001 & & \\
\hline \multirow[t]{3}{*}{$\mathrm{TC}(\mathrm{mg} / \mathrm{dl})$} & Before & $190.48 \pm 35.25$ & -4.67 & $187.25 \pm 27.10$ & -2.18 & 0.123 \\
\hline & after & $180.10 \pm 31.13$ & & $183.03 \pm 28.07$ & & \\
\hline & $P+$ & 0.002 & & 0.09 & & \\
\hline \multirow[t]{3}{*}{ Appetite } & Before & $211.03 \pm 31.68$ & -4.16 & $191.29 \pm 33.95$ & 2.44 & 0.001 \\
\hline & after & $202.06 \pm 34.13$ & & $195 \pm 33.25$ & & \\
\hline & Pt & 0.008 & & 0.064 & & \\
\hline
\end{tabular}

WC waist circumference, $B M I$ body mass index, VEGF vascular endothelial growth factor, $T G$ triglyceride, $L D L$ low density lipoprotein, $H D L$ high density lipoprotein, $T C$ total cholesterol

$+P$ values for paired $t$-test; $\neq P$ values obtained by the comparison of mean differences by independent sample $t$-test. The statistically significant values are presented as italic digits 
Table $\mathbf{5}$ The comparison of studied variables between study groups after adjusting for possible confounders

\begin{tabular}{llll}
\hline Variable & Model 1 & Model 2 & Model 3 \\
\hline Weight $(\mathrm{kg})$ & 0.026 & 0.057 & 0.106 \\
WC $(\mathrm{cm})$ & 0.168 & 0.255 & 0.403 \\
BMl $\left(\mathrm{kg} / \mathrm{m}^{2}\right)$ & 0.017 & 0.038 & 0.038 \\
VEGF $(\mathrm{ng} / \mathrm{l})$ & 0.820 & 0.918 & 0.876 \\
TG $(\mathrm{mg} / \mathrm{dl})$ & 0.394 & 0.513 & 0.533 \\
LDL $(\mathrm{mg} / \mathrm{dl})$ & 0.445 & 0.659 & 0.735 \\
HDL $(\mathrm{mg} / \mathrm{dl})$ & 0.636 & 0.755 & 0.441 \\
TC $(\mathrm{mg} / \mathrm{dl})$ & 0.080 & 0.170 & 0.180 \\
Appetite & 0.004 & 0.012 & 0.019 \\
\hline
\end{tabular}

WC waist circumference, $B M I$ body mass index, VEGF vascular endothelial growth factor, $T G$ triglyceride, $L D L$ low density lipoprotein, $H D L$ high density lipoprotein, TC total cholesterol, Model 1, $P$ values obtained by ANCOVA after adjusting for the variables baseline value, and gender, Model $2, P$ values obtained by ANCOVA after adjusting for the variables baseline value, gender and age, Model 3, $P$ values obtained by ANCOVA after adjusting for the variables baseline value, gender, age and physical activity. The statistically significant values are presented as italic digits

(Table 5); in this model, when variables' baseline value, gender and age were included in the model as confounding variables, weight, BMI and appetite showed significant difference between treatment groups; while when physical activity was also inserted into ANCOVA model, weight lost its significant level, but BMI and appetite remained significant.

\section{Discussion}

Spirulina is a blue-green alga known as nutritious food with a high content of proteins, vitamins, minerals and antioxidants [23-25]. Numerous studies had reported health benefits of Spirulina in some diseases such as anemia, diabetes, arthritis, cancer and cardiovascular disorders [24]. On the other hand, it has been claimed that Spirulina has potential positive effects in therapeutic management of chronic metabolic and non-metabolic disorders [26].

The current study for the first time evaluated the beneficial effects of Spirulina platensis in obesity and its metabolic consequences in obese individuals. We demonstrated anti-obesity effects of this herbal medicine and its therapeutic effects on serum TC and appetite control.

In the present study Spirulina platensis did not have significant effects on serum VEGF in healthy obese individuals in comparison to the control group. Although in a previous animal study, treatment with Spirulina (200 and $400 \mathrm{mg} / \mathrm{kg}$ ) reduced serum VEGF in alkali burn-induced corneal inflammation and neovascularization among rats [17]. Epidemiological studies suggested that obesity is associated with increased levels of adipose tissue derived growth factors like VEGF [27]. Higher plasma levels of VEGF in obese human have been observed by some studies $[9,28]$. It has also been reported that overweight and obese young adult women had a higher plasma level of
unbound-VEGF than lean young adult women [10]. However, some other studies failed to confirm these findings [29]. The discrepancies in findings of different studies could be attributed to difference in the obesity level of participants, the study sample size or the study design.

In the current study we observed a significant reduction in serum TC although other lipids did not changed. Similarly, previous studies reported that 12 weeks of Spirulina supplementation at a dose of $1 \mathrm{~g} /$ day has powerful hypolipidemic effects, especially on the serum triglyceride concentration in dyslipidemic Cretan outpatients [11]. Also, four g/day of Spirulina on Egyptian patients with hyperlipidemia was effective [30]. In another study, Spirulina (4.2 g/day) was added for eight weeks to the diet of 30 Japanese males with high cholesterol, mild hypertension, and hyperlipidemia. It lowered total cholesterol, triglycerides and increased HDL [15]. Possibly Spirulina platensis exerts its hypolipidemic effects via increase in lipoprotein lipase and hepatic triglyceride lipase activity [31]. The hypolipidemic activities of Spirulina platensis has been attributed to its active ingredient Phycocyanin [32]; Phycocyanin is a water soluble protein and enriched in Spirulina. Ingestion of phycocyanin preparation resulted in a significant decrease in serum total cholesterol and atherogenic index whereas serum HDL cholesterol was concurrently increased. Moreover, fecal excretion of cholesterol and bile acid was also increased. It was proposed that decreases in intestinal cholesterol and bile acid absorption following Spirulina platensis feeding may represent a mechanism for the hypocholesterolemic action of its major ingredient [32].

In this study, we mentioned a significant decrease in appetite and consequently weight and BMI in intervention group. The weight reducing effects of Spirulina platensis could be attributed to its appetite reducing effect as observed in the current study. Since gender, age and physical activity could affect the results as confounding parameters, we adjusted the analysis for these parameters by ANCOVA test. We used three models which included gender (model 1), gender and age (model 2), gender, age and physical activity (model 3 ) to reach the goal. The results approved that appetite, weight and BMI reduction was not under the influence of these confounders except "weight" for model 3. A recent study demonstrated that three months of taking of $2 \mathrm{~g}$ /day Spirulina improves BMI and weight as well as blood pressure in overweight patients with hypertension without evidence of cardiovascular disease [33]. In the mentioned study, gender and age were considered as parameters with confounding effects and the results were adjusted for these confounders.

\section{Conclusion}

In conclusion, the findings of the present study demonstrated that Spirulina platensis supplementation at a 
dose of $1 \mathrm{~g}$ daily was effective in weight regulation, serum total cholesterol and appetite reduction. Several limitations of the current study should also be mentioned; low sample size and short period of treatment could be involved in minor discrepancy of our findings with our hypothesis of change in serum VEGF or other lipids. Although the current study was the first one evaluating the healthful beneficial effects of Spirulina platensis in obesity. Further studies with higher dose, sample sized and study duration are warranted.

\section{Abbreviations}

BMI: Body mass index; HDL: High density lipoprotein concentrations; LDL: Low density lipoprotein concentrations; TC: Total cholesterol; VAS: Visual analogue scale; VEGF: Vascular endothelial growth factor; VLDL: Very low density lipoprotein concentrations; WHO: World Health Organization

\section{Acknowledgement}

The current research was financially supported by a grant from Tabriz University of Medical Sciences.

\section{Funding}

This research has been performed by a grant from Tabriz University of Medical Sciences (Project number: 97,820).

\section{Availability of data and materials}

The raw data and other materials in the current study are available for all of the researchers throughout the world for scientific use with kind full permission.

\section{Authors' contributions}

RZ was involved in the data collection and wrote the first draft of the manuscript, MAF conceived and designed the project and revised the draft of the manuscript and performed the statistical analysis, ASH was also involved in the sampling and data collection. All authors read and approved the final manuscript

\section{Competing interest}

The authors declare that there is no conflict of interest.

\section{Consent for publication}

Not applicable.

\section{Ethics approval and consent to participate}

All participants signed a written informed consent approved by the Institutional Review Board of Tabriz University of Medical Sciences. The study design and protocol was approved by the ethical committee of Tabriz University of Medical Sciences (Project number: 97,820). The study has also been registered in Iranian registry of clinical trials (IRCT2015071219082N7; Date registered: September 12, 2015).

\section{Publisher's Note}

Springer Nature remains neutral with regard to jurisdictional claims in published maps and institutional affiliations.

\section{Author details}

'Nutrition Research Center, Department of Nutrition in Community, Faculty of Nutrition, Tabriz University of Medical Sciences, Tabriz, Iran. ${ }^{2}$ Drug Applied Research Center, Nutrition Research Center, Department of Nutrition in Community, Faculty of Nutrition, Tabriz University of Medical Sciences, Tabriz, Iran. ${ }^{3}$ Student Research Committee, Department of Nutrition in Community, Faculty of Nutrition, Tabriz University of Medical Sciences, Tabriz, Iran.

Received: 19 November 2016 Accepted: 8 March 2017

Published online: 21 April 2017

\section{References}

1. Kredel LI, Siegmund B. Adipose-tissue and intestinal inflammation-visceral obesity and creeping fat. Front Immunol. 2014;5:462-74.
2. World Health Organization. Obesity and overweight; fact sheets. Updated June 2016. Available at: http//wwww.who.int/mediacentre/factsheets/fs311/en/

3. Lemoine AY, Ledoux S, Larger E. Adipose tissue angiogenesis in obesity. Thromb Haemost. 2013;110(4):661-8.

4. Hardeman W, Griffin S, Johnston M, Kinmonth A, Wareham N. Interventions to prevent weight gain: a systematic review of psychological models and behaviour change methods. Int Obes Relat Metab Disord. 2000;24(2):131-43.

5. Hasani-Ranjbar S, Zahedi HS, Abdollahi M, Larijani B. Trends in publication of evidence-based traditional Iranian medicine in endocrinology and metabolic disorders. J Diab Metab Disord. 2013;12(1):49-55.

6. Silva SA, Gobbo MG, Pinto-Fochi ME, Rafacho A, Taboga SR, Almeida EA, et al. Prostate hyperplasia caused by long-term obesity is characterized by high deposition of extracellular matrix and increased content of MMP-9 and VEGF. Int J Exp Pathol. 2015;96(1):21-30

7. Piya MK, Harte AL, McTernan PG. Metabolic endotoxaemia: is it more than just a gut feeling? Curr Opin Lipidol. 2013;24(1):78-85.

8. Mick GJ, Wang X, McCormick K. White adipocyte vascular endothelial growth factor: regulation by insulin. Endocrinology. 2002;143(3):948-53.

9. Miyazawa-Hoshimoto S, Takahashi K, Bujo H, Hashimoto N, Saito Y. Elevated serum vascular endothelial growth factor is associated with visceral fat accumulation in human obese subjects. Diabetologia. 2003:46(11):1483-8.

10. Makey KL, Patterson SG, Robinson J, Loftin M, Waddell DE, Miele L, et al. Increased plasma levels of soluble vascular endothelial growth factor (VEGF) receptor 1 (sFlt-1) in women by moderate exercise and increased plasma levels of VEGF in overweight/obese women. European J Cancer Prevent. 2013;22(1):83-9.

11. Mazokopakis EE, Starakis IK, Papadomanolaki MG, Mavroeidi NG, Ganotakis ES. The hypolipidaemic effects of Spirulina (Arthrospira Platensis) supplementation in a Cretan population: a prospective study. J Sci Food Agricul. 2014; 94(3):432-7.

12. Hasler CM. Functional foods: benefits, concerns and challenges- a position paper from the American council on science and health. J Nutr. 2002; 132(12):3772-81.

13. Maranesi M, Barzanti V, Carenini G, Gentili P. Nutritional studies on Spirulina maxima. Acta Vitaminologica Enzymologica. 1983;6(4):295-304.

14. Ibrahim AE, Abdel-Daim MM. Modulating effects of Spirulina Platensis against tilmicosin-induced cardiotoxicity in mice. Cell J (Yakhteh). 2015;17(1):137-44.

15. Torres-Duran PV, Ferreira-Hermosillo A, Juarez-Oropeza MA. Antihyperlipemic and antihypertensive effects of Spirulina Maxima in an open sample of Mexican population: a preliminary report. Lipids Health Dis. 2007:661):33.

16. Marcel A-K, Ekali LG, Eugene S, Arnold OE, Sandrine ED, Von der Weid D, et al. The effect of Spirulina Platensis versus soybean on insulin resistance in HIV-infected patients: a randomized pilot study. Nutrients. 2011;3(7):712-24.

17. Ali EA, Barakat BM, Hassan R. Antioxidant and angiostatic effect of Spirulina Platensis suspension in complete Freund's adjuvant-induced arthritis in rats. PLoS One. 2015;10(4):e0121523.

18. Balasubramanian V SB, Gayasudd in MD, Samreen S.Anti obesity activity of Spirulina Platensis in high fat diet induced rats..Int J Pharmacological Screen Method 2013;3(1):1-5.

19. Flint ARA, Blundell JE, Astrup A. Reproducibility, power and validity of visual analogue scales in assessment of appetite sensations in single test meal studies. Eur J Clin Nutr. 2004;58(2):212-8.

20. Kelishadi RAG, Gheiratmand R, Gouya MM, Razaghi EM, Delavari A, et al. Association of physical activity and dietary behaviors in relation to the body mass index in a national sample of Iranian children and adolescents: CASPIAN study. Bulletin World Health Organ. 2007;85(1):19-26.

21. Kim GWCB, Lee HS, Jung SH, Oh KC, Yoon JU, et al. Comparison analysis of an indirect measurement of Friedwald formula method and direct measurement of immunoseparation method on low-density lipoprotein cholesterol measurement. Korean J Med. 2003;64(1):41-8.

22. Anitha $L$, Chandralekha K. Effect of supplementation of spirulina on blood glucose, glycosylated hemoglobin and lipid profile of male non-insulin dependent diabetics. Asian J Exp Biol Sci. 2010;1:36-46.

23. Sánchez M, Bernal-Castillo J, Rozo C, Rodríguez I. Spirulina (Arthrospira): an edible microorganism: a review. Univ Sci. 2003;8(1):7-24.

24. Chu W-L, Lim Y-W, Radhakrishnan AK, Lim P-E. Protective effect of aqueous extract from Spirulina Platensis against cell death induced by free radicals. BMC Complementary Alternat Med. 2010;10(1):53-61.

25. Sigamani S, Ramamurthy $\mathrm{D}$, Natarajan $\mathrm{H}$. A review on potential biotechnological applications of Microalgae. J App Pharm Sci. 2016;6(8):179-84. 
26. Iyer UM, Dhruv SA, Mani IU. Spirulina and its therapeutic implications as a food product. In Spirulina human nutrition and health. Edited by: Belay A, Gershwin ME. UK: CRC press, Taylor \& Francis Publishing group; 2007. pp. $51-70$.

27. Vona-Davis L. D.P. Rose. Angiogenesis, adipokines and breast cancer. Cytokine Growth Factor Rev. 2009;20(3):193-201.

28. Gomez-Ambrosi JCV, Rodriguez A, Ramirez B, Silva C, Gil MJ, et al. Involvement of serum vascular endothelial growth factor family members in the development of obesity in mice and humans. J Nutr Biochem. 2010;21(8):774-80.

29. Rehman JCR, Bovenkerk JE, Li J, Slavens CA, Jones RM, et al. Obesity is associated with increased levels of circulating hepatocyte growth factor. J Am Coll Cardiol. 2003;41(8):1408-13.

30. El-Sheekh MMHS, Gomaa M. Protective effects of Spirulina on the liver function and hyperlipidemia of rats and human. Braz Arch Biol Technol. 2014:57(1):77-86.

31. Torres-Duran PVM-ZR, Paredes-Carbajal MC, Mascher D, Blé-Castillo J, Díaz-Zagoya JC, et al. Studies on the preventive effect of Spirulina Maxima on fatty liver development induced by carbon tetrachloride, in the rat. J Ethnopharmacol. 1999;64:141-7.

32. Nagaoka SSK, Kaneko H, Shibayama F, Morikawa K, Kanamaru Y, et al. A novel protein C-phycocyanin plays a crucial role in the hypocholesterolemic action of Spirulinaplatensis concentrate in rats. J Nutr. 2005;135(10):2425-30.

33. Miczke AA, Szullnska M, Hansdorfer-Korzon R, Kregielsk-Narozna M, Suliburska J, Walkowiak J, et al. Effects of spirulina consumption on body weight, blood pressure, and endothelial function in overweight hypertensive Caucasians: a double blind, placebo-controlled, randomized trial. Eur Rev Med Pharmacol Sci. 2016;20(1):150-6.

\section{Submit your next manuscript to BioMed Central and we will help you at every step:}

- We accept pre-submission inquiries

- Our selector tool helps you to find the most relevant journal

- We provide round the clock customer support

- Convenient online submission

- Thorough peer review

- Inclusion in PubMed and all major indexing services

- Maximum visibility for your research

Submit your manuscript at www.biomedcentral.com/submit
Biomed Central 